\title{
Deep Eutectic Solvent as a Sustainable Medium for C-C Bond Formation Via Multicomponent Radical Conjugate Additions
}

\author{
Beatriz Saavedra and Diego J. Ramón*
}

Cite This: ACS Sustainable Chem. Eng. 2021, 9, 7941-7947

Read Online

ABSTRACT: Deep eutectic solvents (DESs) have been used for the first time as a sustainable medium in radical-mediated molecular organic synthetic protocols. This study reports an efficient protocol for the $\mathrm{C}-\mathrm{C}$ bond formation through radical conjugate addition of simple olefins (di- and trisubstituted). An inexpensive and abundant iron catalyst $\left[\mathrm{Fe}(\mathrm{acac})_{3}\right]$ together with nontoxic silane (poly(methylhydrosiloxane) (PMHS)) was employed, using choline chloride/ethylene glycol (1:2) as a solvent under air and mild reaction conditions. Different functional groups were well tolerated, and also, the reaction could be carried out on a gram scale with excellent yields.

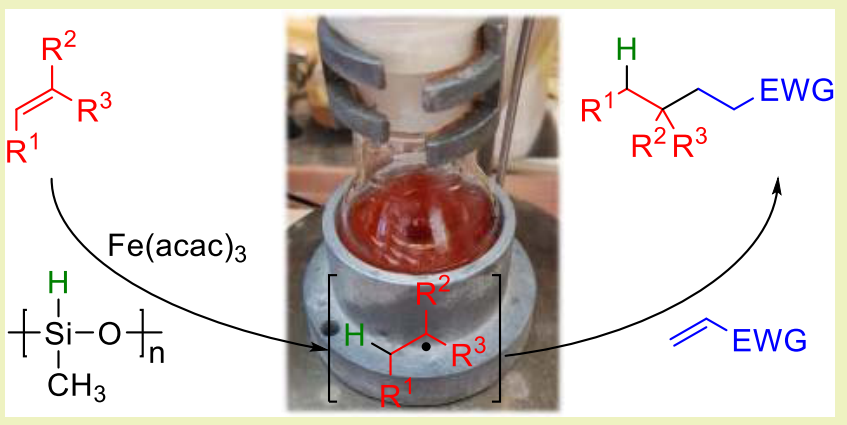

KEYWORDS: deep eutectic solvent, iron catalyst, poly(methylhydrosiloxane), radical coupling, sustainable synthesis

\section{INTRODUCTION}

Radical reactions have gained widespread application for the construction of $\mathrm{C}-\mathrm{C}$ bonds, mainly through the conjugate addition of carbon-centered radicals into unsaturated electrophiles. $^{1-5}$ The development of new methodologies devoted to creating $\mathrm{C}-\mathrm{C}$ bonds in an efficient and sustainable manner would be desirable in the area of green chemistry since it allows the generation of complex molecules of interest as agrochemicals, pharmaceuticals, and polymers. ${ }^{6}$

Among the plethora of carbon radical precursors, olefins represent ideal starting materials since they can be found in a variety of feedstock chemicals and in complex natural compounds, and compared to other radical precursors, are typically bench-stable.

Having this in mind, the application of hydrogen-atom transfer (HAT) to generate carbon-centered radicals from olefins is considered a robust strategy to develop new bondforming reactions in organic synthesis (Scheme 1$)^{7}$

The groups of Drago ${ }^{8}$ and Mukaiyama ${ }^{9,10}$ were pioneers in the use of HAT with alkenes, as radical precursors, by employing nontoxic first-row metals to access the corresponding hydration products. Later, many researchers have expanded the scope of this process to include other electrophiles. ${ }^{11-43}$ However, the potential of these reactions to form $\mathrm{C}-\mathrm{C}$ bonds was not demonstrated until relatively recently, when the Baran group developed a unique method for the direct coupling of unactivated olefins to electron-deficient olefins, both as intraor intermolecular reactions in the presence of an iron catalyst and phenylsilane as a reducing agent. ${ }^{44-48}$ In light of this, a number of other related methodologies have been subsequently reported. ${ }^{49-61}$ However, to date, most of the published methods are far from being environmental benign since these reported procedures employ: (i) toxic and volatile organic solvents, (ii) expensive, air- and moisture-sensitive reducing agents, and (iii) complex and expensive metal catalysts. Thus, the development of efficient HAT reactions, operating under sustainable and green conditions, is still highly sought.

Deep eutectic solvents (DESs) are an emerging class of green solvents, generally referred to combinations of two or more components that form, through electrostatic and strong hydrogen bond interactions, a eutectic liquid mixture at nearly room temperature. ${ }^{62,63}$ These solvents have high thermal stabilities, low volatility, and nonflammability. Most of the components used in their synthesis are naturally occurring, biodegradable, and biorenewable. Furthermore, there are supposed to exist more than one million possible mixtures, affording the possibility of designing a solvent for each different application. Due to their high versatility, tunability, and sustainability, their use as a medium to carry out metalcatalyzed organic transformations has attracted the interest of organic chemists over the last years. ${ }^{64-66}$ However, the change of a typical organic solvent by a DES in a reaction is challenging per se due to the high density of hydrogen bonds

Received: March 31, 2021

Revised: $\quad$ May 20, 2021

Published: June 2, 2021 
Scheme 1. Pioneering Olefin Radical Hydrofunctionalization Reaction

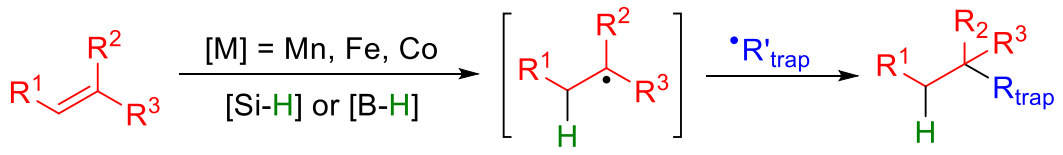

$$
\begin{aligned}
& \bullet_{\text {trap }}^{\prime}=\cdot \mathrm{OH} \\
& \cdot \mathrm{H} \\
& \text { Drago, Mukaiyama } \\
& \text { Magnus, Shenvi, Herzon } \\
& \text { SR } \\
& \text { Girijavallabhan } \\
& \cdot \mathrm{N}(\mathrm{Boc}) \mathrm{NHBoc}, \cdot \mathrm{N}_{3} \cdot \mathrm{Cl}, \cdot \mathrm{CN}, \cdot \mathrm{C}(\mathrm{NOBn}) \mathrm{R} \\
& \text { Carreira } \\
& \cdot \mathrm{N}_{3}, \cdot \mathrm{OH}, \cdot \mathrm{F}, \cdot \mathrm{Cl}, \cdot \mathrm{CN} \text {, etc. } \\
& \text { Boger } \\
& \text { EWG , R-NO }
\end{aligned}
$$

and the ionic character of this neoteric medium that has a big influence on the stability of catalysts and intermediates.

Although DESs have been applied in several organic transformations, the field of radical-mediated organic reactions remains unexplored, with only a few examples related to polymer material synthesis. ${ }^{67-72}$ Herein, we have developed an unprecedented, practical, and sustainable methodology for the multicomponent reductive coupling of a broad range of olefins (including 1,2-disubstituted ones) via radicals, which utilizes (i) a readily available and inexpensive iron catalyst, (ii) poly(methylhydrosiloxane) (PMHS), a cheap, nontoxic, and air- and moisture-stable silane as an effective reducing agent, ${ }^{73}$ and (iii) DESs as a sustainable reaction medium.

\section{RESULTS AND DISCUSSION}

Our initial investigations started by optimizing the reaction conditions, using 1-methylcyclohexene (1a) and methyl acrylate (2a) as a model reaction (Table 1). Different silanes were used as reducing agents, achieving higher yields when using alkoxysilanes instead of phenyl derivatives (entries 1-6). PMHS was selected due to its intrinsic advantages of air and moisture stability, low cost, and nontoxicity. After that, the optimal amount of silane was set at 5.5 equiv (entries 7-10). The reaction time was also evaluated, being noticed that the maximum yield was obtained after $2 \mathrm{~h}$. The increase of the reaction time gave poorer results (see entries 9, 11, and 12). As expected, the reaction failed without a catalyst (entry 13). When $5 \mathrm{~mol} \% \mathrm{Fe}(\mathrm{acac})_{3}$ was used, a $78 \%$ yield was obtained (entry 14), with better results being obtained using $10 \mathrm{~mol} \%$ iron catalyst ( $91 \%$ yield, entry 15 ). However, the further increase of this amount did not produce any significant change (compare entries 6, 9, 14, and 15). The reaction temperature had an important impact: a drop in the yield was observed when the reaction was carried out at $30{ }^{\circ} \mathrm{C}$ (entry 16). The amount of the solvent was reduced to study a possible effect in the reaction. Its decrease resulted in a negative impact on the yield (entry 17), seeming to have a crucial role in the reaction amount of the solvent, as it was previously pointed out for similar processes performed under alcohol solvent conditions. ${ }^{48}$ Other metal catalysts were tested but no catalytic activity was observed (entries 18-24).

Next, different DESs were used as solvents (Figure 1). In general, the presence of an alcohol component in the DES might favor the reaction as previously discussed. In particular, a $\mathrm{ChCl} /$ ethylene glycol $(1: 2)$ eutectic mixture gave the best
Table 1. Optimization of the Reaction Conditions ${ }^{a}$

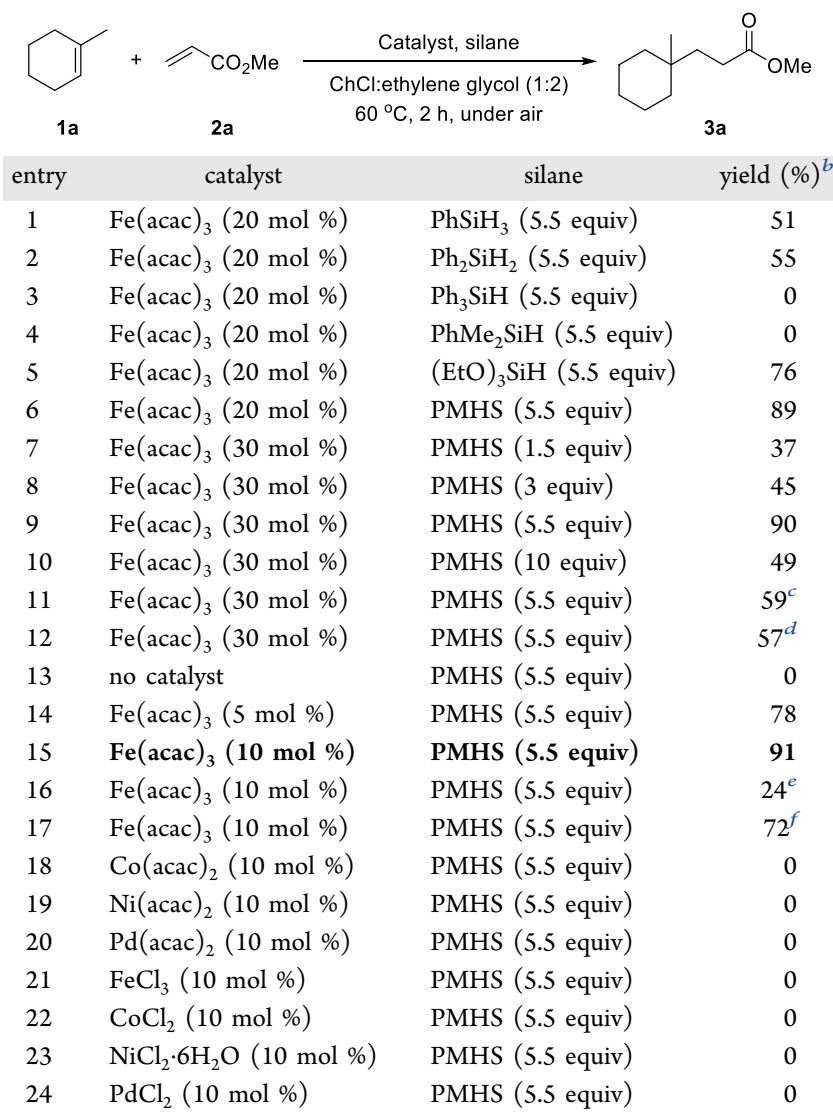

${ }^{a}$ Reaction conditions: compound 1a $(0.3 \mathrm{mmol})$, compound $\mathbf{2 a}(0.9$ $\mathrm{mmol}$ ), silane, and the catalyst in $1.5 \mathrm{~mL}$ of the solvent under air at 60 ${ }^{\circ} \mathrm{C}$ for $2 \mathrm{~h}$. ${ }^{b}$ Yield determined by GC using 4,4'-di-tert-butylbiphenyl (DTBB) as an internal standard. ${ }^{c}$ Reaction performed for $1 \mathrm{~h}$. ${ }^{d}$ Reaction performed for $3 \mathrm{~h}$. ${ }^{e}$ Reaction performed at $30{ }^{\circ} \mathrm{C} .{ }^{f}$ Reaction with $1.0 \mathrm{~mL}$ of the solvent.

result (91\% yield). Common organic solvents were also tested as reaction media (toluene, dimethylformamide (DMF), and dimethyl sulfoxide (DMSO)), but the reaction did not take place in any case. Moreover, other previously employed solvents in this transformation were tested under our optimal reaction conditions, obtaining a $64 \%$ yield with ethanol/ ethylene glycol $(5: 1)$ and a $8 \%$ yield with pure ethanol. ${ }^{44-48}$ Additionally, pure ethylene glycol was used as a solvent 


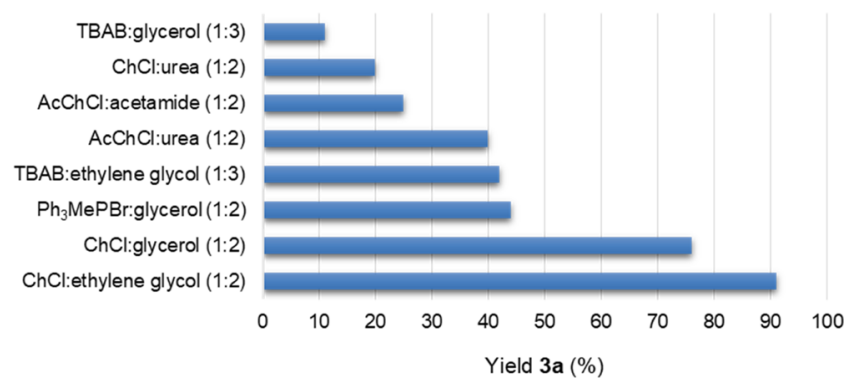

Figure 1. Solvent optimization (TBAB: tetrabutylammonium bromide, $\mathrm{ChCl}$ : choline chloride, and $\mathrm{AcChCl}$ : acetylcholine chloride).

obtaining a $34 \%$ yield, demonstrating that the presence of choline chloride has a positive effect on the reaction media. This fact could be attributed to higher stability of radicals in ionic solvents as previously reported. ${ }^{74,75}$ Meanwhile, the reaction in $\mathrm{FeCl}_{3} /$ glycerol (3:1) failed. All of these results highlight the beneficial use of DESs in terms of reactivity and even sustainability.

Once the best conditions were found (Table 1, entry 15), the scope of the reaction was evaluated. Different acceptor olefins were probed using 1-methylcyclohexene (1a) as donor olefin. Olefins conjugated with esters, ketones, amides, nitriles, and sulfones proved to be competent electron-withdrawing groups in the reaction (Table 2, entries 1-5). Acyclic and

Table 2. Scope of the Reaction Using Trisubstituted Donor Olefins $^{a}$

\begin{tabular}{|c|c|c|c|c|c|}
\hline & $\begin{array}{c}+\mathrm{R}^{1} \mathrm{R}^{2} \\
2\end{array}$ & \multicolumn{2}{|c|}{$\begin{array}{l}\text { ChCl:ethylene glycol (1:2) } \\
60^{\circ} \mathrm{C}, 2 \mathrm{~h} \text {, under air }\end{array}$} & \multicolumn{2}{|l|}{3} \\
\hline entry & compound 1 & $\mathrm{R}^{1}$ & $\mathrm{R}^{2}$ & product & $\begin{array}{l}\text { yield } \\
(\%)^{b}\end{array}$ \\
\hline 1 & 1- & $\mathrm{H}$ & $\mathrm{CO}_{2} \mathrm{Me}$ & $3 a$ & 91 \\
\hline 2 & 1- & $\mathrm{H}$ & $\mathrm{COMe}$ & $3 b$ & 75 \\
\hline 3 & ${ }^{1-}$ methylcyclohexene & $\mathrm{H}$ & $\mathrm{CON}(\mathrm{Me})_{2}$ & $3 c$ & 89 \\
\hline 4 & ${ }^{1-}$ methylcyclohexene & $\mathrm{H}$ & $\mathrm{CN}$ & $3 d$ & 84 \\
\hline 5 & 1- & $\mathrm{H}$ & $\mathrm{SO}_{2} \mathrm{Ph}$ & $3 e$ & $54^{c}$ \\
\hline 6 & 1- & $\mathrm{CO}_{2} \mathrm{Me}$ & $\mathrm{CO}_{2} \mathrm{Me}$ & $3 f$ & 60 \\
\hline 7 & 1- & $-\left(\mathrm{CH}_{2}\right)$ & $\mathrm{O}-$ & $3 g$ & $70^{c}$ \\
\hline 8 & 1- & $-\left(\mathrm{CH}_{2}\right)$ & & $3 \mathrm{~h}$ & $48^{c}$ \\
\hline 9 & $\alpha$-ionone & & & $3 \mathbf{i}$ & 95 \\
\hline
\end{tabular}

${ }^{a}$ Reaction conditions: compound $\mathbf{1}(0.3 \mathrm{mmol})$, compound 2 (0.9 $\mathrm{mmol})$, PMHS (5.5 equiv), and $\mathrm{Fe}(\mathrm{acac})_{3}(10 \mathrm{~mol} \%)$ in $1.5 \mathrm{~mL}$ of $\mathrm{ChCl}$ /ethylene glycol (1:2) under air at $60^{\circ} \mathrm{C}$ for $2 \mathrm{~h} .{ }^{b}$ Isolated yield. ${ }^{c}$ Reaction performed for $5 \mathrm{~h}$.

cyclic disubstituted acceptor olefins gave moderate to good yields (entries 6-8), observing a lower yield when using cyclohexanone as a substrate (entry 8). An intramolecular cyclization was performed using a terpenoid scaffold, $\alpha$-ionone (1b), obtaining the corresponding cyclopropane in an excellent yield (entry 9).
More challenging donor disubstituted olefins were tested using this methodology, obtaining similar results to those using the trisubstituted ones (Table 3). ${ }^{44-48}$ Cyclohexene (1c) was

Table 3. Scope of the Reaction Using Mono- or Disubstituted Donor Olefins ${ }^{a}$

\begin{tabular}{|c|c|c|c|c|c|c|}
\hline \multirow{2}{*}{$\begin{array}{r}1 \\
\text { entry }\end{array}$} & $+\mathrm{R}^{1} \underbrace{\mathrm{R}^{2}}_{\mathrm{R}}$ & \multicolumn{3}{|c|}{$\begin{array}{l}\mathrm{Fe}(\mathrm{acac})_{3}, \mathrm{PMHS} \\
\mathrm{Cl} \text { :ethylene glycol }(1: 2) \\
60^{\circ} \mathrm{C}, 2 \mathrm{~h}, \text { under air }\end{array}$} & \multicolumn{2}{|c|}{$\overbrace{}^{R^{1}}$} \\
\hline & compound 1 & $\mathrm{R}^{1}$ & $\mathrm{R}^{2}$ & $\mathrm{R}^{3}$ & product & $\begin{array}{l}\text { yield } \\
(\%)^{b}\end{array}$ \\
\hline 1 & cyclohexene & $\mathrm{H}$ & $\mathrm{H}$ & $\mathrm{CO}_{2} \mathrm{Me}$ & $3 \mathbf{j}$ & 98 \\
\hline 2 & cyclohexene & $\mathrm{H}$ & $\mathrm{H}$ & $\mathrm{COMe}$ & $3 k$ & 95 \\
\hline 3 & cyclohexene & $\mathrm{H}$ & $\mathrm{H}$ & $\mathrm{CN}$ & 31 & 80 \\
\hline 4 & cyclohexene & $\mathrm{Me}$ & $\mathrm{CO}_{2} \mathrm{Et}$ & $\mathrm{CO}_{2} \mathrm{Et}$ & $3 m$ & 40 \\
\hline 5 & $\begin{array}{l}\text { 3,4-dihydro- } 2 H \text { - } \\
\text { pyran }\end{array}$ & $\mathrm{H}$ & $\mathrm{H}$ & $\mathrm{CO}_{2} \mathrm{Me}$ & $3 n$ & 83 \\
\hline 6 & 1-dodecene & $\mathrm{H}$ & $\mathrm{H}$ & $\mathrm{CO}_{2} \mathrm{Me}$ & 30 & $80^{c}$ \\
\hline 7 & $\begin{array}{l}\text { phenyl vinyl } \\
\text { sulfide }\end{array}$ & $\mathrm{H}$ & $\mathrm{H}$ & $\mathrm{CN}$ & $3 p$ & $80^{d}$ \\
\hline
\end{tabular}

${ }^{a}$ Reaction conditions: compound $\mathbf{1}(0.3 \mathrm{mmol})$, compound 2 (0.9 $\mathrm{mmol})$, PMHS (5.5 equiv), and $\mathrm{Fe}(\mathrm{acac})_{3}(10 \mathrm{~mol} \%)$ in $1.5 \mathrm{~mL}$ of $\mathrm{ChCl}$ /ethylene glycol $(1: 2)$ under air at $60^{\circ} \mathrm{C}$ for $2 \mathrm{~h} .{ }^{b}$ Isolated yield. ${ }^{c}$ Mixture of isomers was observed. ${ }^{d}$ Reaction performed for $5 \mathrm{~h}$.

employed as donor olefin, generating a secondary radical that efficiently reacted with poor alkenes bearing different electronwithdrawing groups such as esters, ketones, or nitriles (entries 1-3). It was observed that the intermolecular coupling is relatively insensitive to sterics since a more sterically hindered olefin gave satisfactory results (Table 3, entry 4). Cyclic enol ethers, as 3, 4-dihydro- $2 \mathrm{H}$-pyran (1d), could be used giving high regioselectivity due to the stabilizing presence of an oxygen atom adjacent to the formed radical (entry 5). Conversely, this radical stabilization was not achieved in the case of 1-dodecene (1e), observing a mixture of isomers with a predominant presence of the product obtained from the secondary radical intermediate.

Finally, another monosubstituted donor olefin attached to a sulfur atom could be coupled with acrylonitrile $(\mathbf{2 d})$ in a good yield (Table 3 , entry 7 ).

The possible recyclability was performed in the standard reaction by decantation of all organic compounds with 2methyltetrahydrofuran (a renewable organic solvent), and the remaining DES and the catalyst were reused in a second cycle obtaining only $43 \%$ of compound $3 a$, with the third cycle failing.

Furthermore, to prove the applicability of the methodology, the reaction was performed on a gram scale (Scheme 2). A slight decrease in the yield was observed probably due to some aggregation of silane observed during the reaction course.

Regarding the reaction mechanism, it was determined that a radical pathway occurs since the reaction was inhibited by the use of a radical scavenger such as 2,2,6,6-tetramethyl-1piperidinyloxy (TEMPO). A TEMPO adduct was detected by ${ }^{1} \mathrm{H}$ NMR (see the Supporting Information (SI)). According to the literature, ${ }^{76-78}$ it was presumed that initially, the solvolysis of a $\mathrm{FeX}_{3}$ precatalyst with an alcoholic solvent generates a catalytical active iron species $\left(\mathrm{X}_{2} \mathrm{Fe}^{\mathrm{III}} \mathrm{OR}\right)$. Then, this catalyst reacts with silane, leading to an iron hydride complex and an alkoxysilane compound. Note that the formation of such a weak bond $(\mathrm{Fe}-\mathrm{H})$ must be compensated 
Scheme 2. Gram-Scale Reaction

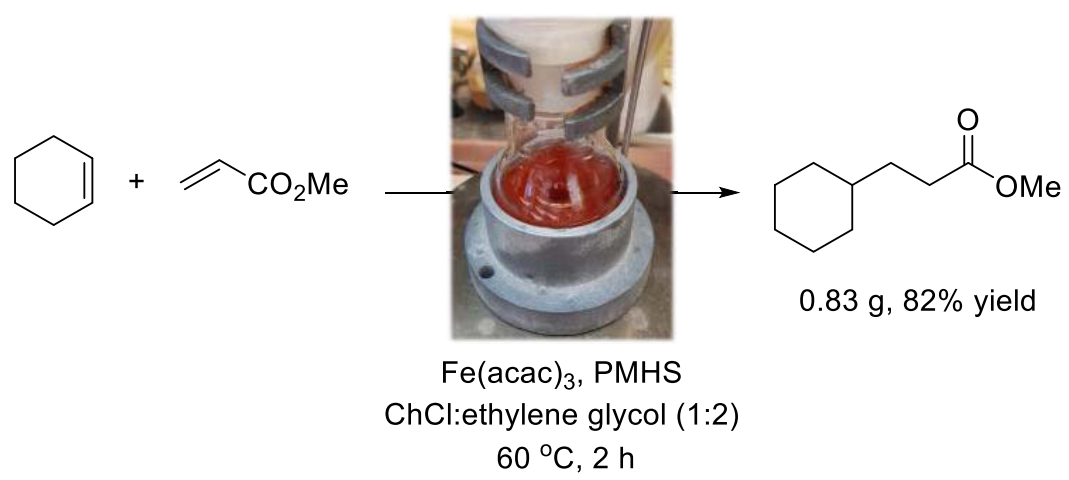

Scheme 3. Proposed Reaction Mechanism

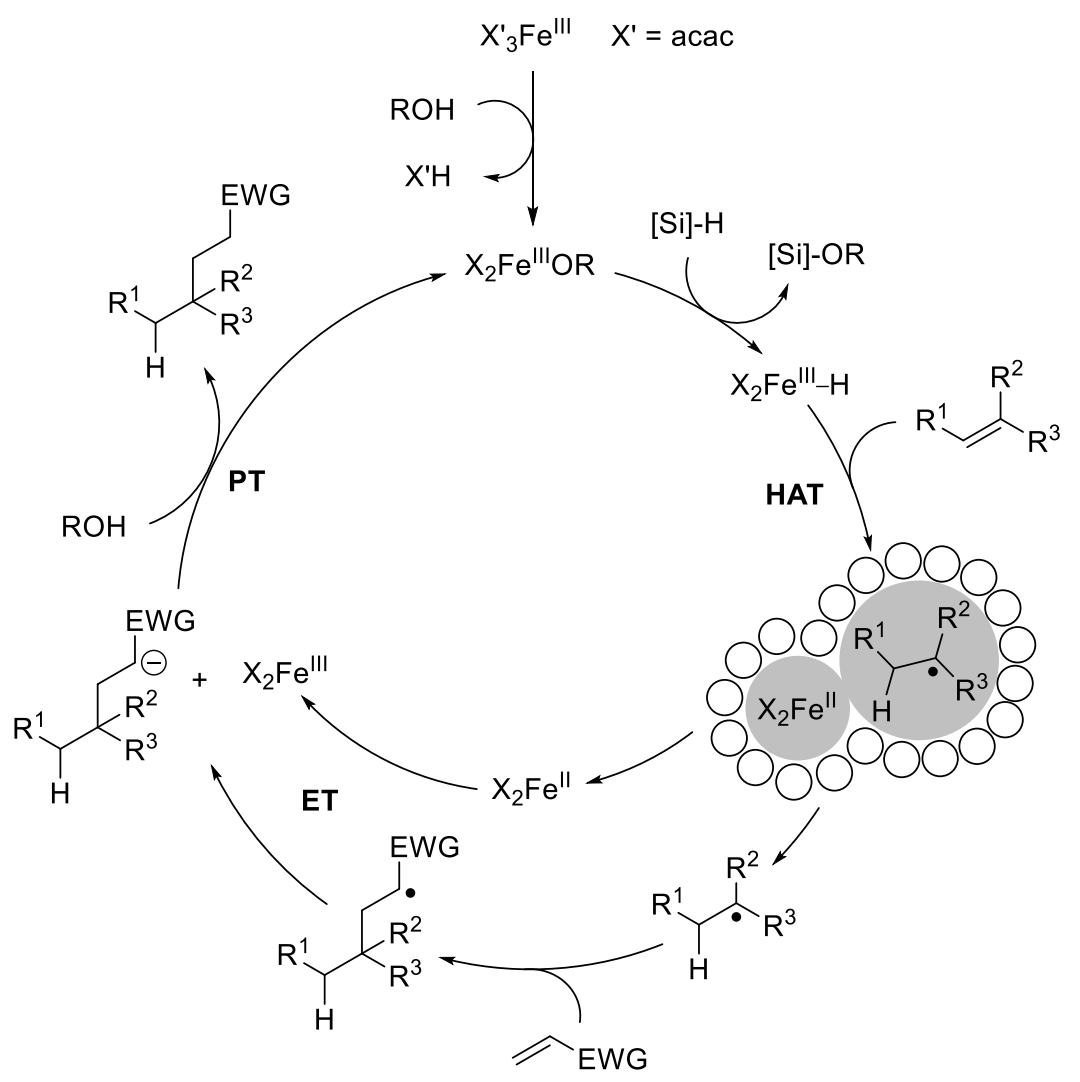

by a strong bond formation in another product ( $\mathrm{Si}-\mathrm{O}$ bond). One important role of ethylene glycol present in the DES might be to generate the catalytically active iron catalyst $\left(\mathrm{X}_{2} \mathrm{Fe}^{\mathrm{III}} \mathrm{OR}\right)$, and consequently, to provide alkoxide that supplies the aforementioned driving force for $\mathrm{Si}-\mathrm{O}$ bond formation. This fact could explain the higher yields observed when diol-based DESs were used as a reaction medium (see Figure 1). The next step involves the hydrogen-atom transfer (HAT) to alkene from the transient iron hydride complex to generate a carbon radical metallo-radical pair surrounded by a "cage" of solvent molecules (Scheme 3). To escape from this pocket, the solvent properties are crucial, so the "strength" of the solvent cage could be tuned through the careful selection of the reaction media. ${ }^{78}$ In concordance with the reported importance of viscosity of solvents in the cage effect, it was noticed that the best result was obtained with the less viscous eutectic mixture but the direct correlation between viscosity and the product yield is not clear (Figure 2). ${ }^{79,80}$

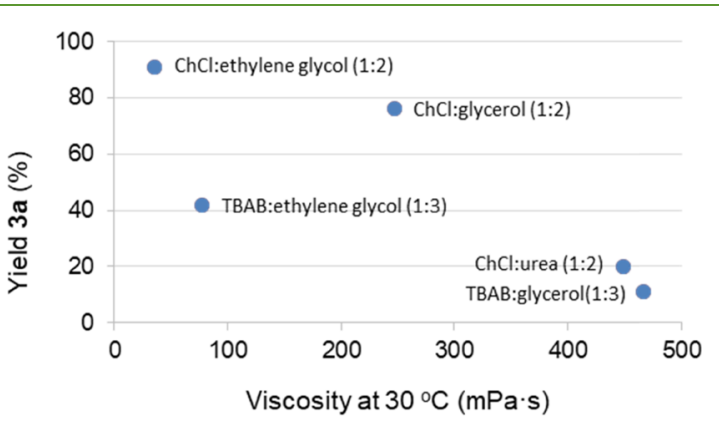

Figure 2. Plot of viscosity ${ }^{62}$ and yield for the radical addition model reaction in DESs.

Thus, DESs have demonstrated to be suitable media that favor the cage escape. It should be noted that homocoupling products were not observed in any case. The released radical is then trapped by an electron-poor acceptor olefin, and the 
formation of a new $\mathrm{C}-\mathrm{C}$ bond generates a product with a radical adjacent to the electron-withdrawing group. Finally, this radical accepts an electron (ET) and a proton from the protic solvent (PT) to afford the desired product.

\section{CONCLUSIONS}

The highly tunable properties of DESs led to the development of an efficient and sustainable methodology for $\mathrm{C}-\mathrm{C}$ bond formation through an iron-catalyzed radical alkene crosscoupling reaction. The use of DESs as solvents in a radical organic synthesis transformation has been described for the first time as having notable advantages compared to previously reported methods. Furthermore, this protocol implies the use of an earth-abundant metal catalyst, an inexpensive, stable, and nontoxic silane in DESs as an environmentally friendly reaction medium under mild and air reaction conditions. A broad range of functionalities were well tolerated and even, 1,2disubstituted olefins gave satisfactory results in comparison with previously reported methodologies. The presence of ethylene glycol and the low viscosity of DES seem to be important factors to get higher yields.

\section{ASSOCIATED CONTENT}

\section{SI Supporting Information}

The Supporting Information is available free of charge at https://pubs.acs.org/doi/10.1021/acssuschemeng.1c02193.

Synthetic procedures, mechanism studies, and characterization data and copies of ${ }^{1} \mathrm{H}$ and ${ }^{13} \mathrm{C}$ NMR (PDF)

\section{AUTHOR INFORMATION}

\section{Corresponding Author}

Diego J. Ramón - Departamento de Química Orgánica and Instituto de Síntesis Orgánica (ISO), Facultad de Ciencias Universidad de Alicante, 03080 Alicante, Spain; (1) orcid.org/0000-0002-6784-0245; Email: djramon@ ua.es

\section{Author \\ Beatriz Saavedra - Departamento de Química Orgánica and Instituto de Síntesis Orgánica (ISO), Facultad de Ciencias Universidad de Alicante, 03080 Alicante, Spain}

Complete contact information is available at: https://pubs.acs.org/10.1021/acssuschemeng.1c02193

\section{Author Contributions}

The manuscript was written through the contributions of all authors. All authors have given approval to the final version of the manuscript.

\section{Notes}

The authors declare no competing financial interest.

\section{ACKNOWLEDGMENTS}

This work was supported by the University of Alicante (VIGROB-316FI) and the Spanish Ministerio de Economia, Industria y Competitividad (PGC2018-096616-B-100). B.S. thanks Generalitat Valenciana (ACIF/2017/211) for her fellowship.

\section{REFERENCES}

(1) Hoffmann, R. W. Markovnikov free radical addition reactions, a sleeping beauty kissed to life. Chem. Soc. Rev. 2016, 45, 577-583.
(2) Yan, M.; Lo, J. C.; Edwards, J. T.; Baran, P. S. Radicals: reactive intermediates with translational potential. J. Am. Chem. Soc. 2016, $138,12692-12714$.

(3) Huang, X.-J.; Qin, F.-H.; Liu, Y.; Wu, S.-P.; Li, Q.; Wei, W.-T. Acylation/cyclization of 1,6-dienes with ethers under catalyst- and base-free conditions. Green Chem. 2020, 22, 3952-3955.

(4) Liu, Y.; Meng, Y.-N.; Huang, X.-J.; Qin, F.-H.; Wu, D.; Shao, Q.; Guo, Z.; Li, Q.; Wei, W.-T. Radical cyclization of 1,6-dienes with azobis(alkylcarbonitriles) on water under additive-free conditions. Green Chem. 2020, 22, 4593-4596.

(5) Qin, F.-H.; Huang, X.-J.; Liu, Y.; Liang, H.; Li, Q.; Cao, Z.; Wei, W.-T.; He, W.-M. Alcohols controlled selective radical cyclization of 1,6-dienes under mild conditions. Chin. Chem. Lett. 2020, 31, 32673270.

(6) Krische, M. J. Metal Catalyzed Reductive C-C Bond Formation: A Departure from Preformed Organometallic Reagents; Springer: Berlin, 2007.

(7) Crossley, S. W.; Obradors, C.; Martinez, R. M.; Shenvi, R. A. $\mathrm{Mn}-, \mathrm{Fe}-$, and Co-catalyzed radical hydrofunctionalizations of olefins. Chem. Rev. 2016, 116, 8912-9000.

(8) Zombeck, A.; Hamilton, D. E.; Drago, R. S. Novel catalytic oxidations of terminal olefins by cobalt (II)-Schiff base complexes. J. Am. Chem. Soc. 1982, 104, 6782-6784.

(9) Mukaiyama, T.; Isayama, S.; Inoki, S.; Kato, K.; Yamada, T.; Takai, T. Oxidation-reduction hydration of olefins with molecular oxygen and 2-propanol catalyzed by bis (acetylacetonato) cobalt (II). Chem. Lett. 1989, 18, 449-452.

(10) Mukaiyama, T.; Yamada, T. Recent advances in aerobic oxygenation. Bull. Chem. Soc. Jpn. 1995, 68, 17-35.

(11) Magnus, P.; Payne, A. H.; Waring, M. J.; Scott, D. A.; Lynch, V. Conversion of $\alpha, \beta$-unsaturated ketones into $\alpha$-hydroxy ketones using an MnIII catalyst, phenylsilane and dioxygen: acceleration of conjugate hydride reduction by dioxygen. Tetrahedron Lett. 2000, 41, 9725-9730.

(12) Magnus, P.; Waring, M. J.; Scott, D. A. Conjugate reduction of $\alpha, \beta$-unsaturated ketones using an MnIII catalyst, phenylsilane and isopropyl alcohol. Tetrahedron Lett. 2000, 41, 9731-9733.

(13) Crossley, S. W.; Barabé, F.; Shenvi, R. A. Simple, chemoselective, catalytic olefin isomerization. J. Am. Chem. Soc. 2014, 136, 16788-16791.

(14) Iwasaki, K.; Wan, K. K.; Oppedisano, A.; Crossley, S. W.; Shenvi, R. A. Simple, chemoselective hydrogenation with thermodynamic stereocontrol. J. Am. Chem. Soc. 2014, 136, 1300-1303.

(15) Green, S. A.; Matos, J. L.; Yagi, A.; Shenvi, R. A. Branchselective hydroarylation: iodoarene-olefin cross-coupling. J. Am. Chem. Soc. 2016, 138, 12779-12782.

(16) Obradors, C.; Martinez, R. M.; Shenvi, R. A. Ph (i-PrO) SiH2: an exceptional reductant for metal-catalyzed hydrogen atom transfers. J. Am. Chem. Soc. 2016, 138, 4962-4971.

(17) Green, S. A.; Vásquez-Céspedes, S.; Shenvi, R. A. Iron-nickel dual-catalysis: a new engine for olefin functionalization and the formation of quaternary centers. J. Am. Chem. Soc. 2018, 140, 1131711324.

(18) Matos, J. L.; Vásquez-Céspedes, S.; Gu, J.; Oguma, T.; Shenvi, R. A. Branch-selective addition of unactivated olefins into imines and aldehydes. J. Am. Chem. Soc. 2018, 140, 16976-16981.

(19) Green, S. A.; Huffman, T. R.; McCourt, R. O.; van der Puyl, V.; Shenvi, R. A. Hydroalkylation of olefins to form quaternary carbons. J. Am. Chem. Soc. 2019, 141, 7709-7714.

(20) King, S. M.; Ma, X.; Herzon, S. B. A method for the selective hydrogenation of alkenyl halides to alkyl halides. J. Am. Chem. Soc. 2014, 136, 6884-6887.

(21) Ma, X.; Herzon, S. B. Non-classical selectivities in the reduction of alkenes by cobalt-mediated hydrogen atom transfer. Chem. Sci. 2015, 6, 6250-6255.

(22) Ma, X.; Herzon, S. B. Intermolecular hydropyridylation of unactivated alkenes. J. Am. Chem. Soc. 2016, 138, 8718-8721. 
(23) Ma, X.; Dang, H.; Rose, J. A.; Rablen, P.; Herzon, S. B. Hydroheteroarylation of unactivated alkenes using $\mathrm{N}$-methoxyheteroarenium salts. J. Am. Chem. Soc. 2017, 139, 5998-6007.

(24) Girijavallabhan, V.; Alvarez, C.; Njoroge, F. G. Regioselective cobalt-catalyzed addition of sulfides to unactivated alkenes. J. Org. Chem. 2011, 76, 6442-6446.

(25) Waser, J.; Carreira, E. M. Convenient synthesis of alkylhydrazides by the cobalt-catalyzed hydrohydrazination reaction of olefins and azodicarboxylates. J. Am. Chem. Soc. 2004, 126, 56765677.

(26) Waser, J.; Carreira, E. M. Catalytic hydrohydrazination of a wide range of alkenes with a simple Mn complex. Angew. Chem., Int. Ed. 2004, 43, 4099-4102.

(27) Waser, J.; González-Gómez, J. C.; Nambu, H.; Huber, P.; Carreira, E. M. Cobalt-catalyzed hydrohydrazination of dienes and enynes: Access to allylic and propargylic hydrazides. Org. Lett. 2005, 7, 4249-4252.

(28) Waser, J.; Nambu, H.; Carreira, E. M. Cobalt-catalyzed hydroazidation of olefins: convenient access to alkyl azides. J. Am. Chem. Soc. 2005, 127, 8294-8295.

(29) Waser, J.; Gaspar, B.; Nambu, H.; Carreira, E. M. Hydrazines and azides via the metal-catalyzed hydrohydrazination and hydroazidation of olefins. J. Am. Chem. Soc. 2006, 128, 11693-11712.

(30) Gaspar, B.; Carreira, E. M. Mild cobalt-catalyzed hydrocyanation of olefins with tosyl cyanide. Angew. Chem., Int. Ed. 2007, 46, 4519-4522.

(31) Gaspar, B.; Waser, J.; Carreira, E. M. Cobalt-Catalyzed Synthesis of Tertiary Azides from $\alpha, \alpha$-Disubstituted Olefins under Mild Conditions Using Commercially Available Reagents. Synthesis 2007, 2007, 3839-3845.

(32) Gaspar, B.; Carreira, E. M. Catalytic Hydrochlorination of Unactivated Olefins with para-Toluenesulfonyl Chloride. Angew. Chem., Int. Ed. 2008, 47, 5758-5760.

(33) Gaspar, B.; Carreira, E. M. Cobalt catalyzed functionalization of unactivated alkenes: regioselective reductive $\mathrm{C}-\mathrm{C}$ bond forming reactions. J. Am. Chem. Soc. 2009, 131, 13214-13215.

(34) Ishikawa, H.; Colby, D. A.; Boger, D. L. Direct coupling of catharanthine and vindoline to provide vinblastine: total synthesis of (+)-and ent-(-)-vinblastine. J. Am. Chem. Soc. 2008, 130, 420-421. (35) Ishikawa, H.; Colby, D. A.; Seto, S.; Va, P.; Tam, A.; Kakei, H.; Rayl, T. J.; Hwang, I.; Boger, D. L. Total synthesis of vinblastine, vincristine, related natural products, and key structural analogues. J. Am. Chem. Soc. 2009, 131, 4904-4916.

(36) Barker, T. J.; Boger, D. L. Fe(III)/NaBH4-mediated free radical hydrofluorination of unactivated alkenes. J. Am. Chem. Soc. 2012, 134, $13588-13591$.

(37) Gotoh, H.; Sears, J. E.; Eschenmoser, A.; Boger, D. L. New insights into the mechanism and an expanded scope of the Fe (III)mediated vinblastine coupling reaction. J. Am. Chem. Soc. 2012, 134, 13240-13243.

(38) Leggans, E. K.; Barker, T. J.; Duncan, K. K.; Boger, D. L. Iron(III)/NaBH4-mediated additions to unactivated alkenes: synthesis of novel $20^{\prime}$-vinblastine analogues. Org. Lett. 2012, 14, 14281431.

(39) Baik, T.-G.; Luis, A. L.; Wang, L.-C.; Krische, M. J. Diastereoselective cobalt-catalyzed aldol and Michael cycloreductions. J. Am. Chem. Soc. 2001, 123, 5112-5113.

(40) Wang, L.-C.; Jang, H.-Y.; Roh, Y.; Lynch, V.; Schultz, A. J.; Wang, X.; Krische, M. J. Diastereoselective cycloreductions and cycloadditions catalyzed by co $(\mathrm{dpm}) 2$-silane $(\mathrm{dpm}=2,2,6,6$ tetramethylheptane-3, 5-dionate): mechanism and partitioning of hydrometallative versus anion radical pathways. J. Am. Chem. Soc. 2002, 124, 9448-9453.

(41) Shigehisa, H.; Aoki, T.; Yamaguchi, S.; Shimizu, N.; Hiroya, K. Hydroalkoxylation of unactivated olefins with carbon radicals and carbocation species as key intermediates. J. Am. Chem. Soc. 2013, 135, 10306-10309.
(42) Shigehisa, H.; Nishi, E.; Fujisawa, M.; Hiroya, K. Cobaltcatalyzed hydrofluorination of unactivated olefins: a radical approach of fluorine transfer. Org. Lett. 2013, 15, 5158-5161.

(43) Shigehisa, H.; Koseki, N.; Shimizu, N.; Fujisawa, M.; Niitsu, M.; Hiroya, K. Catalytic hydroamination of unactivated olefins using a Co catalyst for complex molecule synthesis. J. Am. Chem. Soc. 2014, 136, 13534-13537.

(44) Lo, J. C.; Gui, J.; Yabe, Y.; Pan, C.-M.; Baran, P. S. Functionalized olefin cross-coupling to construct carbon-carbon bonds. Nature 2014, 516, 343-348.

(45) Lo, J. C.; Yabe, Y.; Baran, P. S. A practical and catalytic reductive olefin coupling. J. Am. Chem. Soc. 2014, 136, 1304-1307.

(46) Dao, H. T.; Li, C.; Michaudel, Q.; Maxwell, B. D.; Baran, P. S. Hydromethylation of unactivated olefins. J. Am. Chem. Soc. 2015, 137, 8046-8049.

(47) Gui, J.; Pan, C.-M.; Jin, Y.; Qin, T.; Lo, J. C.; Lee, B. J.; Spergel, S. H.; Mertzman, M. E.; Pitts, W. J.; La Cruz, T. E.; et al. Practical olefin hydroamination with nitroarenes. Science 2015, 348, 886-891.

(48) Lo, J. C.; Kim, D.; Pan, C.-M.; Edwards, J. T.; Yabe, Y.; Gui, J.; Qin, T.; Gutiérrez, S.; Giacoboni, J.; Smith, M. W.; et al. Fe-catalyzed $\mathrm{C}-\mathrm{C}$ bond construction from olefins via radicals. J. Am. Chem. Soc. 2017, 139, 2484-2503.

(49) Bordi, S.; Starr, J. T. Hydropyridylation of olefins by intramolecular Minisci reaction. Org. Lett. 2017, 19, 2290-2293.

(50) Liang, B.; Wang, Q.; Liu, Z.-Q. A Fe (III)/NaBH4-promoted free-radical hydroheteroarylation of alkenes. Org. Lett. 2017, 19, 6463-6465.

(51) Shen, Y.; Huang, B.; Zheng, J.; Lin, C.; Liu, Y.; Cui, S. CspCsp3 Bond Formation via Iron (III)-Promoted Hydroalkynylation of Unactivated Alkenes. Org. Lett. 2017, 19, 1744-1747.

(52) Qi, J.; Zheng, J.; Cui, S. Fe (III)-catalyzed hydroallylation of unactivated alkenes with morita-baylis-hillman adducts. Org. Lett. 2018, 20, 1355-1358.

(53) Saladrigas, M.; Bosch, C.; Saborit, G. V.; Bonjoch, J.; Bradshaw, B. Radical Cyclization of Alkene-Tethered Ketones Initiated by Hydrogen-Atom Transfer. Angew. Chem., Int. Ed. 2018, 57, 182-186.

(54) Saladrigas, M.; Loren, G.; Bonjoch, J.; Bradshaw, B. Hydrogen atom transfer (HAT)-triggered iron-catalyzed intra-and intermolecular coupling of alkenes with hydrazones: access to complex amines. ACS Catal. 2018, 8, 11699-11703.

(55) Turner, O. J.; Murphy, J. A.; Hirst, D. J.; Talbot, E. P. A. Hydrogen Atom Transfer-Mediated Cyclisations of Nitriles. Chem. Eur. J. 2018, 24, 18658-18662.

(56) Liu, S.; Shen, T.; Luo, Z.; Liu, Z.-Q. A free radical alkylation of quinones with olefins. Chem. Commun. 2019, 55, 4027-4030.

(57) Saladrigas, M.; Bonjoch, J.; Bradshaw, B. Iron Hydride Radical Reductive Alkylation of Unactivated Alkenes. Org. Lett. 2020, 22, 684-688.

(58) Tardieu, D.; Desnoyers, M.; Laye, C.; Hazelard, D.; Kern, N.; Compain, P. Stereoselective Synthesis of C,C-Glycosides from exoGlycals Enabled by Iron-Mediated Hydrogen Atom Transfer. Org. Lett. 2019, 21, 7262-7267.

(59) Wang, Y.-Y.; Bode, J. W. Olefin amine (OLA) reagents for the synthesis of bridged bicyclic and spirocyclic saturated N-heterocycles by catalytic hydrogen atom transfer (HAT) reactions. J. Am. Chem. Soc. 2019, 141, 9739-9745.

(60) Zhang, H.; Zhan, X. Y.; Chen, X. L.; Tang, L.; He, S.; Shi, Z. C.; Wang, Y.; Wang, J. Y. Iron (III) Chloride/Phenylsilane-Mediated Cascade Reaction of Allyl Alcohols with Maleimides: Synthesis of Poly-Substituted $\gamma$-Butyrolactones. Adv. Synth. Catal. 2019, 361, 4919-4925.

(61) Kattamuri, P. V.; West, J. G. Hydrogenation of Alkenes via Cooperative Hydrogen Atom Transfer. J. Am. Chem. Soc. 2020, 142, 19316-19326.

(62) Ramón, D. J.; Guillena, G. Deep Eutectic Solvents: Synthesis, Properties, and Applications; Wiley-VCH: Weinheim, 2019.

(63) Hansen, B. B.; Spittle, S.; Chen, B.; Poe, D.; Zhang, Y.; Klein, J. M.; Horton, A.; Adhikari, L.; Zelovich, T.; Doherty, B. W.; Gurkan, B.; Maginn, E. J.; Ragauskas, A.; Dadmun, M.; Zawodzinski, T. A.; 
Baker, G. A.; Tuckerman, M. E.; Savinell, R. F.; Sangoro, J. R. Deep Eutectic Solvents: A Review of Fundamentals and Applications. Chem. Rev. 2021, 121, 1232-1285.

(64) Smith, E. L.; Abbott, A. P.; Ryder, K. S. Deep Eutectic Solvents (DESs) and Their Applications. Chem. Rev. 2014, 114, 11060-11082.

(65) García-Álvarez, J. Deep Eutectic Mixtures: Promising Sustainable Solvents for Metal-Catalyzed and Metal-Mediated Organic Reactions. Eur. J. Inorg. Chem. 2015, 2015, 5147-5157.

(66) Alonso, D. A.; Baeza, A.; Chinchilla, R.; Guillena, G.; Pastor, I. M.; Ramón, D. J. Deep Eutectic Solvents: The Organic Reaction Medium of the Century. Eur. J. Org. Chem. 2016, 2016, 612-632.

(67) Carriazo, D.; Serrano, M. C.; Gutiérrez, M. C.; Ferrer, M. L.; del Monte, F. Deep-eutectic solvents playing multiple roles in the synthesis of polymers and related materials. Chem. Soc. Rev. 2012, 41, 4996-5014.

(68) Mota-Morales, J. D.; Sánchez-Leija, R. J.; Carranza, A.; Pojman, J. A.; del Monte, F.; Luna-Bárcenas, G. Free-radical polymerizations of and in deep eutectic solvents: Green synthesis of functional materials. Prog. Polym. Sci. 2018, 78, 139-153.

(69) Jablonský, M.; Škulcová, A.; Šima, J. Use of deep eutectic solvents in polymer chemistry-A review. Molecules 2019, 24, 3978.

(70) Ndizeye, N.; Suriyanarayanan, S.; Nicholls, I. A. Polymer synthesis in non-ionic deep eutectic solvents. Polym. Chem. 2019, 10, 5289-5295.

(71) Pereira, V. A.; Mendonça, P. V.; Coelho, J. F. J.; Serra, A. C. Liquid salts as eco-friendly solvents for atom transfer radical polymerization: a review. Polym. Chem. 2019, 10, 4904-4913.

(72) Quirós-Montes, L.; Carriedo, G. A.; García-Álvarez, J.; Presa Soto, A. Deep eutectic solvents for Cu-catalysed ARGET ATRP under an air atmosphere: a sustainable and efficient route to poly(methyl methacrylate) using a recyclable $\mathrm{Cu}(\mathrm{ii})$ metal-organic framework. Green Chem. 2019, 21, 5865-5875.

(73) Cano, R.; Yus, M.; Ramon, D. J. Impregnated palladium on magnetite as catalyst for multicomponent reductive amination reactions and other related reducing processes. Tetrahedron 2011, 67, 8079-8085.

(74) Strehmel, V. Radicals in Ionic Liquids. ChemPhysChem 2012, 13, 1649-1663.

(75) Wylie, L.; Seeger, Z. L.; Hancock, A. N.; Izgorodina, E. I. Increased stability of nitroxide radicals in ionic liquids: more than a viscosity effect. Phys. Chem. Chem. Phys. 2019, 21, 2882-2888.

(76) Jiang, H.; Lai, W.; Chen, H. Generation of Carbon Radical from Iron-Hydride/Alkene: Exchange-Enhanced Reactivity Selects the Reactive Spin State. ACS Catal. 2019, 9, 6080-6086.

(77) Kim, D.; Rahaman, S. M. W.; Mercado, B. Q.; Poli, R.; Holland, P. L. Roles of Iron Complexes in Catalytic Radical Alkene CrossCoupling: A Computational and Mechanistic Study. J. Am. Chem. Soc. 2019, 141, 7473-7485.

(78) Shevick, S. L.; Wilson, C. V.; Kotesova, S.; Kim, D.; Holland, P. L.; Shenvi, R. A. Catalytic hydrogen atom transfer to alkenes: a roadmap for metal hydrides and radicals. Chem. Sci. 2020, 11, 1240112422.

(79) Barry, J. T.; Berg, D. J.; Tyler, D. R. Radical Cage Effects: Comparison of Solvent Bulk Viscosity and Microviscosity in Predicting the Recombination Efficiencies of Radical Cage Pairs. J. Am. Chem. Soc. 2016, 138, 9389-9392.

(80) Barry, J. T.; Berg, D. J.; Tyler, D. R. Radical Cage Effects: The Prediction of Radical Cage Pair Recombination Efficiencies Using Microviscosity Across a Range of Solvent Types. J. Am. Chem. Soc. 2017, 139, 14399-14405. 